www.jmscr.igmpublication.org Impact Factor 5.244

Index Copernicus Value: 83.27 ISSN (e)-2347-176x ISSN (p) 2455-0450 crossref DOI: _https://dx.doi.org/10.18535/jmscr/v4i12.31

\title{
Impact of Health Education Intervention on Uptake of Random Screening for Cervical \& Breast Cancers among Rural Women in Villages of Gurgaon Cluster, Haryana, India
}

\author{
Authors \\ P. Cheena Chawla*, Anil Kumar Chawla, Seema Chaudhary \\ Corresponding Author* \\ P. Cheena Chawla \\ World Healthal Trust, 34, Knowledge Park 1, Greater Noida -201310 \\ Email: pcheena@gmail.com, Phone: +91-9818921035
}

\begin{abstract}
Disease awareness and socio-cultural practices together influence the treatment-seeking behavior of rural women as well as their uptake for preventive screening of breast and cervical cancers. This study was carried out to assess the awareness and knowledge of rural women about cervical and breast cancers and their attitude and uptake for primary screening of these cancers in villages of Gurgaon, randomly selected by our financial partner, DLF Foundation, Gurgaon. A cross-sectional study was conducted among 603 women, aged 21-65 years, who attended the awareness and screening camps on women's cancers where random primary screening for breast and cervical cancers was done. Out of 603 women who participated in different camps held at various villages of Gurgaon, during 2014-2016, a volunteer sample comprising 235 women (39\%) were screened for cervical and breast cancers. Further, 365 women (61\%) were taught how to conduct self-breast examination. There were 88 cases (37.44\%) out of 235 screened who were found to have genital infections for which they were given free medicines. Out of 235 screened women, 99 were suspected (42\%) to have abnormalities in cervix or breast and were recommended for advanced tests (46 women for Pap smear test, 33 women for USG Abdomen and 20 cases for Mammography) for disease confirmation and guidance for proper treatment. Only 38 cases, however, adhered to the follow-up schedule. Specially designed, easy-tounderstand leaflets (in Hindi) on the four women's cancers (Endometrial Cancer, Breast Cancer, Ovarian Cancer and Cervical Cancer) were distributed to all participating women. The main finding was that rural women had poor knowledge about cervical and breast cancer screening and there was complete lack of awareness regarding the symptoms, risk factors and preventive screening of these cancers. Effective education and large-scale primary screening are necessary for alleviating the burden of cervical and breast cancers in India. It came to light that low family income and lack of transport contribute to women's inability to reach health centres when faced with distressing symptoms of these cancers. The study concluded that cancer awareness programmes along with on-site primary screening of cervical and breast cancers, using simple, cost-effective techniques, would significantly benefit rural women as a majority of them never get a preventive screening done for these cancers.
\end{abstract}

Keywords: Cervical/Breast Cancer, Awareness, Preventive Screening, Follow-up. 


\section{INTRODUCTION}

Cancer is considered to be a fatal disease, despite the type, in both developed and developing countries of the world. Cervical and breast cancers are the two most common cancers affecting women worldwide. Knowledge about symptoms, risk factors, preventive screening and early detection can significantly reduce cancer-related deaths. There is high mortality in rural areas due to late diagnosis as patients usually present at an advanced stage because of lack of awareness, low educational level, low family income, inability to access healthcare services, shyness and lack of requisite facilities for screening and treatment of these cancers in primary health centers. According to one study, the major reasons for not doing cancer screening tests, in urban areas, were: ignorance $(50 \%)$, lethargic attitude $(44.8 \%)$ and lack of time (34.6\%) (Shankar et al, 2015). A cross-sectional study was conducted in Vypin Block of Ernakulam District, Kerala, India where four of the seven Panchayats were randomly chosen and 809 women were interviewed from four Panchayats. Majority of respondents $(89.2 \%)$ did not know any risk factor for cervical cancer. Of the 809 women studied, only 6.9 per cent had undergone screening due to various factors.

Fatima Isa Modibbo et al 2016, explored the barriers to cervical cancer screening, focusing on religious and cultural factors among Muslim and Christian women in Nigeria, in order to inform group-specific interventions that may improve uptake of cervical cancer screening programmes. Participants mentioned religious and cultural obligations of modesty, gender of healthcare providers, fear of disclosure of results, fear of infections, lack of awareness, discrimination at hospitals, and need for spousal approval as barriers to uptake of screening. In this light, the present study was aimed to ascertain the level of awareness on women's cancers, besides assessing the need for primary, random cancer screening among the rural women living in village clusters of Gurgaon, Haryana, India.
Lack of education, scarce healthcare facilities and socio-cultural factors majorly influence the uptake for preventive cancer screening and early treatment. Therefore, advocacy, communication and community mobilization (ACSM) are essential components of screening cum awareness campaigns for combating cancer, especially among the rural populations. Such efforts can increase public access to information about preventable cancers, thus motivating people to undergo preventive screening and treatment at early stages to win over these cancers. This study aimed to determine the effect of health education on enhancing knowledge and awareness about cancer, resulting in higher uptake of preventive screening for cervical and breast cancers among rural women inhabiting the villages of Gurgaon, Haryana, India.

Annually, there are nearly 1.4 lakh new cases and 70,000 deaths due to cervical cancer in India (ICO Information Centre on HPV and Cancer). The most important risk factor associated with cervical cancer is Human Papillomavirus (HPV) infection. Inadequacy of accessible cervical cancer screening services is a major barrier to screening uptake. Other risk factors are early marriage (below age 20 years), early age at sexual contact, multiple partners, polygamy, poor personal hygiene and general health and lack of awareness of the disease (Kumar et al, 2008, P Cheena Chawla et al, 2014a), none of which have been proven to be the only cause of this disease. Many of these factors tend to be based on socioeconomic conditions relating to poverty and lack of education in whom the risk factors are most prevalent. Cancer of the cervix can be completely prevented by providing early and regular cervical detection services for all women who have been sexually active. This can be done by the HPV test, Pap smear test or the Visual Inspection with Acetic Acid (VIA), which is affordable and more sensitive (RTCOG, 2003).

Breast cancer is the most common female malignancy and is commonly associated with high levels of morbidity and mortality due to late 
presentation. Breast self-examination (BSE) can help in early detection of the disease. Breast screening with mammography, once every three years, is normally recommended for women above 40, where X-ray of the breasts is done to detect tumors before they become palpable lumps (Wardle et al, 2015).

There is also disproportionate skilled manpower and technology in India with respect to available cancer specialists, trained staff and specialized cancer centers across India. Thus delivery of affordable, quality and equitable cancer care in India is a big challenge. In one study done by $\mathrm{P}$. Cheena Chawla et al 2014b, the scenario of existing facilities in hospitals (Private \& Government) and Primary Health Centers (PHCs) of Delhi-NCR region for the detection and treatment of cervical cancer is brought to light. This study clearly shows the deficit of gynecologists in PHCs, while they have adequate trained paramedical staff. The facilities were found to be significantly lacking in the 80 PHCs in comparison with hospitals surveyed in DelhiNCR region for both screening and treatment of cervical cancer. ask what to do There is an urgent need of recruitment of trained staff at government hospitals and PHCs for screening and treatment of cervical cancer. As early detection and timely treatment is the sure key to alleviate the burden of cancers in our society, in circumstances where healthcare resources are deficient, resources should be directed towards alternative, affordable strategies. Creating awareness is crucial to the success of these affordable cervical cancer prevention programmes. It improves the uptake of cervical and breast cancer preventive screening.

\section{MATERIAL AND METHODS}

To prevent the high occurrence of cancers among rural women, several community awareness programmes and screening health camps have been conducted by World Healthal Trust (WHT), in collaboration with DLF Foundation, Gurgaon under the Project 'DLF-WHT Cancer Awareness and Screening Camps- 2014-15 \& 2015-16' at villages of Gurgaon, with facilities of registration, counseling, screening and referral. The main objective was to spread awareness about the causes, risk factors, striking symptoms, precautions, importance of early screening and timely treatment of cervical and breast cancers, while screening the registered women for early signs of breast and cervical cancer using primary screening methods. The ultimate goal was to promote cancer prevention among rural women, reduce the number of deaths caused due to these cancers and provide timely treatment to those affected.

Several public awareness/advocacy programmes for women were organized in different villages of Gurgaon: Sakatpur, Nawada-Fatehpur, Hyatpur, Shikopur, Hasanpur, besides in DLF Cyber-City and Ridge Valley School, Gurgaon. In all the camps, scientists from World Healthal Trust addressed the gathering and sensitized women about the prevalence of the four women's cancers (cervical, breast, ovarian and endometrial cancers) in our country, their risk factors and symptoms associated with each of the cancers and importance of early screening and timely treatment. A few days prior to the camp, World Healthal Trust with support of DLF Foundation distributed 2000 pamphlets in the village households besides putting up several banners in the near-by areas of village to promote maximum participation for the event. Specially designed, easy-to-understand leaflets (in Hindi) on all the four women's cancers were also distributed among the audience. All queries of the general public related to the four women's cancers were answered by scientists and gynecologists present at the event. Posters on cervical and breast cancer (size: $23 " \times 36 "$, four colour) for the general public (in both English \& Hindi) and pamphlets for disseminating key messages on cancer prevention \& management (in both English \& Hindi) were also pasted at multiple locations for easy readability. All women were requested to spread information about these four cancers, which only affected women, in their community. 
After the advocacy round, the women were requested to register themselves for getting screened for cervical and breast cancers. The screening of cervical cancer was done by gynecologists on-board using Visual Inspection with Acetic Acid (VIA) method for the detection of pre-cancerous lesions in the cervix, which turn aceto-white by the application of freshly prepared $3-5 \%$ acetic acid to the cervix area. Cervical cancer screening using VIA can be offered in remote, less equipped clinics, thereby reaching more women. Another important advantage is that VIA provides immediate results, making it possible to screen and either treat or refer women during the same visit (Cervical Cancer Prevention Initiatives at PATH). For breast cancer detection, the screening method used was breast physical examination (BPE). Women found to be positive for any abnormalities or early signs of cervical or breast cancer were recommended for further advanced screening by Pap smear test and Ultrasound/Mammography respectively.

\section{RESULTS}

Women actively participated on the specified days of camps as prior publicity of the event was done covering all near-by areas. A total of 603 women, aged 21-65 years, attended the awareness and screening camps where random screening of women for breast and cervical cancers was done using primary screening methods. Out of 603 women, a volunteer sample comprising 235 women (39\%) who willingly got registered for screening, were screened for cervical and breast cancers. Out of these 235 screened women, 88 cases $(37.44 \%)$ received free medicines for vaginal infections (cervical erosion, acute cervicitis and foul smell etc.). This can be attributed to poor genital hygiene and presence of sexually transmitted diseases (STDs) especially among the rural community. There were 99 suspect cases $(42 \%)$ who were detected to have some abnormalities in cervix or breast, and were referred for advanced tests (46 women for Pap smear test, 33 women for USG Abdomen + Pelvic and 20 cases for Mammography) in order to confirm the disease. In all, the follow-up monitoring was done for 38 women to ensure their adherence to treatment up to complete recovery. Additionally, a total of 365 women (61\%) were taught how to conduct self-breast examination.
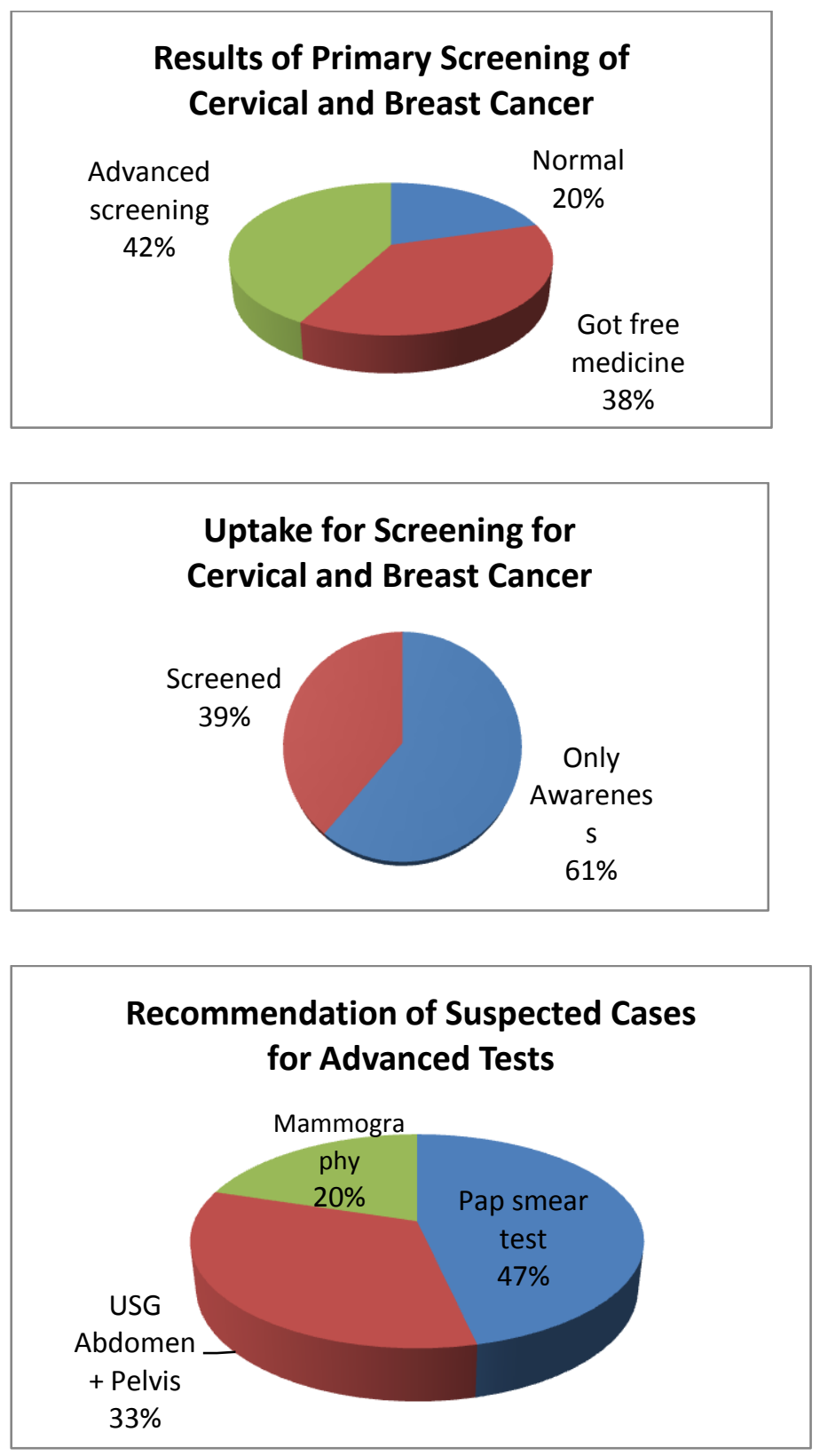

\section{CONCLUSION}

The study population had no knowledge about women's cancers. Not a single woman attending these camps knew anything about preventive screening with VIA/Pap smear test for cervical cancer or breast self-examination to detect early signs of breast cancer. The increasing incidence of cancer cases and mortality, which are extremely 
alarming, are attributed to this lack of awareness. The increase in cancer cases is more in developing countries as compared to that in developed countries (Jamel, et al., 2011) because as cancer is detected mostly at late stages in most developing countries, it poses several challenges in treatments, recovery and survival (Rabeta Mohd Salleh, et al., 2011).

Screening for early detection of cancer of the breast and cervix in the rural areas is suboptimal. This evidence-based information constitutes an advocacy tool for policy making and development of appropriate intervention. Primary health care workers need to improve on their outreach services and train peers to cascade training to the community women and enhance dissemination of timely information to the patients about routine preventive cancer screening. This study also showed significant improvement in the intervention groups' perception of cervical and breast cancer. They were better able to appreciate their individual risk of cervical and breast cancers. All the participating women agreed that women with any vaginal and breast abnormalities should visit the hospital without delay.

A preventive approach coupled with timely effective treatment is the only solution to this formidable challenge of combating cancer. The study concluded that clubbing awareness programmes with on-site screening of cervical and breast cancers would significantly benefit those women who have never had a preventive test for these cancers done before, as suspect cases of these cancers can be easily diagnosed by simple, cost-effective primary techniques. There is an urgent need to gear up efforts to communicate accurate information, among different strata of society, about common preventable cancers, especially breast and cervical cancers, that are the leading cause of death in women due to cancer (P. Cheena Chawla et al. 2014a).

In order to stimulate regular screening among women, there should be an aggressive health promotion intervention, designed to increase awareness and to correct impressions about cervical and breast cancer in the community. There should be State-funded awareness drives, with appropriate education and communication strategies, including preventive screening for all women in their reproductive years. Effective education and mass screening are necessary for successful cervical and breast cancer screening programme in India as creation of awareness and improving access to screening services are crucial to alleviating the burden of these common preventable cancers. Importantly, the outcome of such screening would guide management of conditions throughout life, including the decisionmaking process, in which the individual would be an important part. Interventions to promote culturally sensitive public health programmes designed to provide information and services that cut across different age groups, educational levels, cultures and social strata should be developed and implemented.

\section{ACKNOWLEDGEMENT}

The study was conducted with CSR-grant of DLF Foundation Gurgaon. We are thankful to Lt. Gen. Rajender Singh, the CEO, Mr. Ritesh Sinha, Director, Village Cluster Development Program, and Roopee Sahaee, Deputy Manager - CSR at DLF Foundation for their encouragement and constant support. We would also like to show our gratitude to Doctor Dr. Reena Sinha and paramed staff of DLF PHCs, our colleagues Akansha Mehra, Sanjeev Sharma for their assistance and valuable contribution in Implementation of the study. We would extend our sincere gratitude to Dr. Nimmi Chautani, Professor \& Head, School of Medical Sciences and Research, Sharda University, Greater Noida for ever ready to arrange the gynecologist for screening women with VIA and BPE to detect suspect cases of cervical and breast cancers respectively.

\section{REFERENCES}

1. Shankar A, Rath G, Roy S, Malik
A, Bhandari
$\mathrm{R}$, Kishor
K, Barnwal
$\mathrm{K}$, Upadyaya
S, Srivastava V, Singh R. 
Level of awareness of cervical and breast cancer risk factors and safe practices among college teachers of different states in india: do awareness programmes have an impact on adoption of safe practices? Asian Pac J Cancer Prev.2015;16(3):927-32.

2. S. Aswathy, Mariya Amin Quereshi, Beteena Kurian, and K. Leelamoni. Cervical cancer screening: Current knowledge \& practice among women in a rural population of Kerala, India. Indian $\mathbf{J}$ Med Res. 2012 Aug; 136(2): 205-210.

3. Isa Modibbo F, Dareng E, Bamisaye P, et al. Qualitative study of barriers to cervical cancer screening among Nigerian women. BMJ Open 2016; 6: e008533. doi:10.1136/bmjopen-2015- 008533

4. Human Papillomavirus and Related Cancers, Fact Sheet 2016 (June 14, 2016). ICO Information Centre on HPV and Cancer. http://www.hpvcentre.net/statistics/reports/ IND_FS.pdf

5. Kumar V, Abbas AK, Fausto N, Mitchel RN: Robbins Basic Pathology. 2007, London: WB Saunders Elsevier, 718-721. 8

6. P. Cheena Chawla, Anil Chawla, Seema Chaudhary, Richa Shrivastava and Anju Shrivastava, Community Sensitization Of Women Cancers Through Awareness Cum Screening Programme- A Pilot Study," Journal of International Academic Research for Multidisciplinary, 2014a, (2) 21-30.

7. Royal Thai College of Obstetricians and Gynaecologists

(RTCOG)/JHPIEGO Cervi-cal Cancer Prevention Group: Safety, acceptability, and feasibility of a single-visit approach to cervical cancer prevention in rural Thailand: a demonstration project. Lancet. 2003, 361: 814-820.

8. Jane Wardle, Kathryn Robb., Sally Vernon, Jo Waller. Screening for Prevention and Early Diagnosis of Cancer, 2015 American Psychological Association 0003-066X/15 Vol. 70, No. 2, 119-133
9. P. Cheena Chawla, Anil Kumar Chawla, Richa Shrivastava, Anju Shrivastava, Seema Chaudhary, "Situation Analysis of Existing Facilities for Screening, Treatment and Prevention of Cervical Cancer in Hospitals/Primary health Centers of Delhi-NCR Region, India," Asian Pacific Journal of Cancer Prevention, 2014b (15) 5479-5482.

10. Mo PKH, Mak WWS, Chong ESK, Shen H, Cheung RYM (2014) The Prevalence and Factors for Cancer Screening Behavior among People with Severe Mental Illness in Hong Kong. PLoS ONE 9(9): e107237.

11. Juszczyk, D., Simon, A. E., Waller, J., Ramirez, A. J., \& Wardle, J. (2011). Do the UK public realise that colorectal cancer is a common cancer? Colorectal Disease, 13(2), 227-228. doi:10.1111/j.1463-1318.2010.02489.x

12. Jamel, A., Bray, F., Center, M. M., Ferlay, J., Ward, E., \& Forman, D. (2011). Global cancer statistics. CA Cancer J Clin, 61, 6990. http://dx.doi.org/10.3322/caac.20107

13. Salleh, R. M., Shahar, S., Ghazali, A. R., Haron, N., \& Koon, P. B. (2011). Risk factor for breast cancer among women in Klang Valley, Malaysia. Health and the Environment Journal, 2(2), 29-33.

14. Wong, L. P., Wong, Y. L., Low, W. Y., Khoo, E. M., \& Shuib, R. (2009). Knowledge and awareness of cervical cancer and screening among Malaysian women who have never had a Pap smear: A qualitative study. Singapore Medical Journal, 50(1), 49-53.

15. P. Cheena Chawla, "Role of Healthcare Providers in Patient Education on HPV Infection and Cervical Cancer Prevention A Cross-Sectional Study in Public \& Private Health Centers of Delhi-NCR, India" International Journal of Latest Research in Science and Technology, 2014 (3) $140-146$. 